\title{
Estudo comparativo da condição de saúde bucal de idosos não institucionalizados de Governador Valadares-MG, com a meta proposta pela Organização Mundial de Saúde para 2010
}

$1{ }^{1}$ Caroline Magalhães Alcântara, ${ }^{2}$ Carlos Alberto Dias,

${ }^{3}$ Suely Maria Rodrigues, ${ }^{4}$ Fabiola Alves dos Reis I

Resumo: O objetivo deste estudo foi comparar a condição de saúde bucal de idosos não institucionalizados de Governador Valadares-MG com a meta da Organização Mundial de Saúde (OMS) para o ano 2010. Foi utilizado o banco de dados desenvolvido pelo grupo de pesquisa Saúde, Indivíduo e Sociedade (SAIS), da Universidade Vale do Rio Doce (UNIVALE). Avaliaramse o acesso aos serviços odontológicos, o índice CPO-D e o uso e necessidade de prótese em 505 idosos. Em relação ao acesso aos serviços odontológicos, 61,8\% dos idosos afirmaram não terem ido ao dentista nos últimos 12 meses que antecederam a entrevista. Destes, 37,9\% relataram ter procurado o sistema público por motivo de consulta de rotina, reparos e manutenção protética. O resultado do índice CPO-D encontrado foi de 27,9. Quanto ao uso e a necessidade de prótese, constatou-se que $46,9 \%$ dos idosos utilizavam a total removível, 33,3\% não utilizavam nenhum tipo, 54,1\% não apresentavam necessidade de uso e $23,8 \%$ necessitavam de prótese total removível. Diante dos dados obtidos, conclui-se que a condição de saúde bucal dos idosos avaliados é precária, encontrando-se distante do padrão estabelecido pelas metas da OMS para o ano 2010. Essa ocorrência aponta para a necessidade de investimentos na área da saúde bucal, para que em longo prazo as metas sejam atingidas.

> Palavras-chave: idosos; saúde bucal; Organização Mundial de Saúde.
1 Odontóloga. Graduada pela Universidade Vale do Rio Doce.

2 Psicólogo, Doutor em Psicologia Clínica pela Université de Picardie Jules Verne - França, professor de Psicologia Clínica e Assessor de Pesquisa e Pós-Graduação (APPG) da Universidade Vale do Rio Doce - MG.

\footnotetext{
${ }^{3}$ Odontóloga. Doutora em Saúde Coletiva pela Universidade Federal de Minas Gerais (UFMG). Professora e pesquisadora integrante do núcleo de pesquisa Saúde, Indivíduo e Sociedade (SAIS) da Universidade Vale do Rio Doce - MG.

${ }^{4}$ Odontóloga. Doutora em Bases Gerais da Cirurgia. Professora e Pró-Reitora acadêmica da Universidade Vale do Rio Doce - MG.
} 
A epidemiologia busca reconhecer as causas que influenciam o padrão de distribuição de doenças e dos agravos à saúde, assim como de seus determinantes. Com o envelhecimento da população brasileira, criou-se a necessidade do conhecimento sobre as condições de saúde bucal dos idosos. Esse conhecimento visa à criação de práticas de aperfeiçoamento no âmbito da odontogeriatria. Essa disciplina surgiu há 50 anos nos EUA e, a partir daí, passou a ser conhecida internacionalmente na condição de especialidade profissional definida (VIEIRA, 2003; ANTUNES; PERES, 2006).

A população idosa é alvo de alterações fisiológicas e patológicas com as quais tem que aprender lidar. Vale salientar que, em relação às alterações patológicas, estas passam de agudas a crônicas, requerendo cuidados continuados e custosos. Essa situação é agravada por problemas como doenças infecciosas e a desnutrição, ainda persistentes no país (RAMOS;VERAS; KALACHE, 1987).

A literatura atual sobre a saúde bucal do idoso tende a salientar que a cárie dentária, as doenças periodontais, as abrasões a presença de lesões, o câncer bucal e o edentulismo são ocorrências comuns nessa faixa etária. Essas alteraçôes podem variar devido aos fatores fisiológicos individuais do processo de envelhecimento, como a diminuição da capacidade mastigatória, a dificuldade de deglutição, a secura na boca, as modificações no paladar e a perda de dimensão vertical, independentemente de se tratar de idosos institucionalizados ou não (CARNEIRO et al., 2005; SILVA; VALSECKI JUNIOR, 2000).

As condiçõos de saúde bucal dos idosos não foi, durante séculos, um tema de importância nas discussões voltadas para a saúde. Sendo assim, o alto índice de edentulismo decorre do fato de que, por muito tempo, as más condiçôes bucais desse grupo foram consideradas como normais em decorrência do avanço da idade (PUCCA JÚNIOR, 2002).

A meta da Organização Mundial da Saúde (OMS) havia previsto que, para o ano 2000, na faixa etária de 65-74 anos, 50\% das pessoas deveriam contar com pelo menos vinte dentes em condições funcionais. Apesar dos investimentos feitos no tocante a prevenção de cárie, principalmente das crianças em idade escolar, tal meta não foi alcançada. A literatura registrou um índice CPOD de 27,2 para a faixa etária de 50-59 anos, sendo que os dentes extraídos predominaram, com 86\%. É 
preocupante pensar que atingir os índices considerados favoráveis para a saúde bucal faz parte de uma realidade distante da vivenciada no Brasil. Deve-se considerar que as perdas dentárias encontradas na população idosa atual são decorrentes de políticas ineficazes de atenção à saúde bucal, que antecederam a implantação dos programas de cuidados a saúde do idoso (FDI, 1982, apud COLUSSI; FREITAS, 2002; BRASIL, 1988, apud COLUSSI; FREITAS, 2002).

Em decorrência disso, não há ainda como avaliar a eficácia das novas políticas, sobretudo se estas não contemplarem uma educação em Saúde Bucal dirigida a crianças, jovens e adultos. É a partir dessa ação que tais indivíduos poderão ter maior cuidado à saúde, cujos efeitos benéficos serão sentidos quando atingirem a terceira idade. A valorização dos dentes pela criança e pelo adulto no futuro depende do modo como isso é repassado pelos pais durante a infância de seus filhos. $O$ fato dos idosos não terem recebido, durante sua infância e adolescência, uma educação adequada nesse campo faz com que, na atualidade, não se sintam estimulados a buscar a atenção disponível nas unidades de saúde. A isso se pode acrescentar a demora e a baixa qualidade desse tipo de atendimento, promovendo influência direta no acentuado déficit na procura do serviço pela população (DIAS et al., 2008).

No final de 1993, aconteceu na Suécia o $4^{\circ}$ Congresso Mundial de Odontologia. Nesse evento, a OMS traçou como meta, para o ano de 2010, um CPO-D de, no máximo, um dente cariado, perdido ou obturado para crianças de 12 anos. Foi também previsto que todos os indivíduos com 18 anos deveriam ter todos os dentes; $90 \%$ da população entre 35 e 44 anos deveriam permanecer com 20 dentes ou mais; e apenas $5 \%$ da população na faixa etária entre 65 e 74 anos, deveriam apresentar edentulismo (BRASIL, 2003).

Por ser uma atividade voltada para sujeitos, e que exige cuidados e conhecimentos específicos, o cirurgião dentista deve estar consciente de que a odontogeriatria é um novo campo de atuação para o qual deve se preparar. Essa especialidade tende a ganhar cada vez mais espaços no mercado de trabalho brasileiro com o passar dos anos. Para se fortalecer como especialidade, mais estudos devem ser feitos, focalizando as dificuldades encontradas no atendimento a esse grupo populacional. Deve-se atentar para a importância do atendimento multidisciplinar como possibilidade de uma maior compreensão do sujeito e de suas necessidades, assegurando um atendimento mais eficaz (MONTENEGRO, 2003). 
O objetivo deste estudo é comparar a condição de saúde bucal de idosos não institucionalizados, residentes em Governador Valadares-MG, com a meta estabelecida pela Organização Mundial de Saúde (OMS) para o ano 2010.

\section{Revisão da literatura}

\section{Crescimento da população idosa no Brasil}

Por "idoso", entende-se: indivíduos que possuem 60 anos ou mais, tal como preconiza a Política Nacional do Idoso e o Estatuto do Idoso. O grande aumento do número de indivíduos dessa faixa etária, além de ser observado nos países desenvolvidos, é também perceptível naqueles em desenvolvimento. No Brasil, esse fenômeno é atribuído à alta fecundidade ocorrida no período de 1950 a 1970 e à redução da mortalidade da população idosa. Mais especificamente, esse quadro é resultante da associação de diversos fatores, a saber: melhoria nas condições de vida da população; controle da mortalidade infantil e da natalidade; aumento dos programas de medidas preventivas de saúde geral; campanhas de vacinação; e principalmente, avanços nas diversas áreas da medicina (MORAES, 2008; BRASIL, 2003).

Juntamente com a população idosa, crescerá o número de doenças crônicas, assim como o de incapacidades, resultando num maior e mais prolongado uso dos serviços de saúde. Tal situação sugere um planejamento de educação, prevenção e promoção de saúde voltada não apenas para os idosos, mas também para aqueles que irão envelhecer (FILHO; RAMOS, 1999).

Nos últimos 60 anos, o número absoluto de idosos aumentou em nove vezes. Em 1940, esse número era de 1,7 milhões e, em 2000, de 14,5 milhões. Em 2006, as pessoas com 60 anos de idade ou mais alcançaram 19 milhões, correspondendo a $10,2 \%$ da população total do país. Projeta-se para 2020 um contingente de aproximadamente 30,9 milhóes de pessoas com 60 ou mais anos (BELTRÃO; CAMARANO; KANSO, 2004; IBGE, 1998).

A esperança de vida dos indivíduos com mais de 60 anos aumentou no período de 1980 a 2000. Tal ocorrência, em termos relativos, foi maior do que os ganhos obtidos pela população total. O crescimento acelerado da população idosa brasileira é particularmente observado na região Sudeste. Isso pode ser um reflexo do maior desenvolvimento socioeconômico dessa região em relação às demais (CAMARANO, 2002; CAMPOS, 2004). 
O segmento que mais cresce no país é o dos indivíduos com idade acima de 80 anos. A visibilidade desse fenômeno é pequena devido ao fato de que esse contingente populacional representou apenas $1 \%$ do total da população brasileira no ano 2000. Contudo, deve-se estar atento para o fato de que esse quadro tende a ser diferente, considerando a elevação do contingente de idosos nos últimos anos (CAMARANO, 2006).

Essa transição demográfica nos mostra a necessidade de mudanças na capacitação profissional no que diz respeito ao atendimento integral da saúde do idoso. A preocupação com as técnicas e peculiaridades próprias desse atendimento deve tornar-se cada vez mais importante. Vale ressaltar que cada ser humano envelhece de maneira particular. Esse fato demonstra que a realidade social em que o indivíduo está inserido tem forte relação com sua expectativa de vida, pois o grupo socioeconômico ao qual pertence determina o estilo e a qualidade em que vive essa população (HAMILTON, 2002).

$\mathrm{O}$ envelhecimento é uma ocorrência de grande complexidade: exige mais dos serviços de saúde e demanda cuidados permanentes. Além das alterações nas relaçōes familiares, econômicas e funcionais, que sugerem adaptações dos serviços de saúde, as reações emocionais decorrentes da nova situação vivenciada pelos sujeitos, devem também ser alvo de atenção. Estas são determinantes na identificação de melhores condutas a serem adotadas pelos profissionais na atenção a esse grupo populacional. Como não há um meio de interromper o processo de envelhecimento, os profissionais devem estar aptos a torná-lo confortável (TOMMASI, 1987; GIACOMIN et al., 2005).

Os desafios trazidos pelo envelhecimento da população têm diversas dimensôes e dificuldades. Influenciam o consumo, a transferência de capital e de propriedades, o recolhimento de impostos, o pagamento de pensões, o mercado de trabalho, a saúde e assistência médica e a composição e organização da família. Em contrapartida, os idosos contribuem de maneira significativa na renda das famílias em relação à população mais jovem. Quando se encontram na condição de chefes de família assumem a responsabilidade sobre filhos e netos. Estes, em função das dificuldades de inserir-se no mercado de trabalho, se acomodam à situação (MORAES, 2008).

Diferente do que se pensa, o envelhecimento não é sinônimo de doença, mas sim um processo fisiológico natural e irreversível. Logo, nada mais justo do que 
garantir ao idoso a sua integração na comunidade. Para isso, o envelhecimento da população brasileira não deve ser tratado apenas no âmbito médico, e sim com a implementação de recursos que atendam as suas necessidades, bem como a criação de novas Instituições de Longa Permanência.

Também no setor social, econômico e ambiental, algumas mudanças são necessárias. Os projetos rumo à criação de universidades abertas para a terceira idade têm se firmado cada vez mais. A título de exemplo vale citar o programa da UnATI/UERJ (Universidade da Terceira Idade, da Universidade do Estado do Rio de Janeiro). Este tem por objetivo contribuir para uma melhor compreensão da lógica de promoção da saúde do idoso (VERAS; CALDAS, 2004).

Em 2000, dos 14,5 milhões de idosos, 55,0\% eram do sexo feminino, refletindo uma taxa de crescimento mais elevada desse segmento, em relação ao masculino. Um homem que chegou aos 60 anos pode esperar viver mais 13,1 anos, e uma mulher, mais 15,4 anos (CAMARANO, 2006).

\section{A condição de saúde bucal do idoso brasileiro e os planos de atenção governamental}

Com o aumento na proporção de idosos no Brasil, aumentou também a ocorrência de problemas de saúde, com repercussóes na qualidade de vida desse grupo populacional. Entre estes, são citadas as más condições de saúde bucal, relacionadas a problemas de ordem nutricional, cardiovascular, dentre outros. No Brasil, destacam-se atualmente condições inadequadas de saúde bucal na população idosa, que apresenta altos índices de dentes cariados, perdidos e obturados (CPOD), e elevada frequência de edentulismo e necessidade de próteses. No entanto, os estudos epidemiológicos de saúde bucal em idosos, em geral, se restringem a grupos específicos, como os institucionalizados e os usuários de serviços de saúde. (SILVA; VALSECKI JR, 2000; COLUSSI; FREITAS, 2002).

Em todo o país, estudos direcionados à condição bucal de idosos são escassos. Os que foram realizados até então apresentam como alteraçôes mais prevalentes o edentulismo, as lesões cariosa coronária e radicular, as periodontopatias e as lesões em tecidos moles. Dentre os brasileiros com mais de sessenta anos, em cada grupo de quatro idosos, três não têm dentes em pelo menos uma das arcadas, o que corresponde a $75,0 \%$, revelando o quadro deficiente das políticas preventivas direcionadas a todos os grupos etários (CARNEIRO, 2005; IBGE/PNAD, 1998). 
É evidente que o aumento das oportunidades de acesso odontológico para idosos faria diminuir os altos índices de cárie e doença periodontal do país. A atenção aos pacientes idosos deve ser realizada dentro de uma perspectiva holística e, sobretudo, interdisciplinar, uma vez que o tratamento dispensado a estes difere significativamente daquele exigido para os mais jovens. Durante muitos anos, a atenção odontológica no serviço público brasileiro caracterizouse por prestar assistência a grupos populacionais restritos, principalmente na faixa etária escolar, de 06 a 12 anos. $\mathrm{O}$ restante da população ficava excluído e dependente de serviços meramente curativos e mutiladores. Isso resultava na dificuldade de acesso à assistência odontológica e numa baixa cobertura de atendimento (ETTINGER, 1987; BARROS; BERTOLDI, 2002).

Porém, com a implantação do Sistema Único de Saúde (SUS), e definidos os princípios que deveriam nortear o novo sistema, surgiu um grande desafio para a saúde bucal coletiva: reformular suas práticas para responder às diretrizes do SUS, deixando no passado o caráter mutilador. A solução para esse problema requer do governo interesse e investimento, principalmente na área de promoção e educação em saúde, visando à prevenção (BARROS; BERTOLDI, 2002).

A Constituição Federal de 1988 garantiu a todos o direito universal de acesso à saúde, mas a efetivação desse direito se deu apenas a partir da implantação do SUS em 1990. O SUS investe, anualmente, 260 milhôes de reais no atendimento odontológico, prevendo pelo menos uma equipe de saúde bucal para cada equipe de saúde da família (BRASIL, 2000).

Para produzir informações sobre as condições de saúde bucal da população brasileira em 2000, foi desenvolvido o Projeto SB - Brasil. De maneira geral, os resultados observados não foram positivos. O Brasil atingiu as metas da OMS para o ano 2000 somente no que se refere às crianças com 12 anos de idade. Para as demais idades, os níveis ficaram aquém das metas propostas para o ano avaliado (BRASIL, 2003).

Em outubro de 2004, o Ministério da Saúde implantou a Política Nacional de Saúde Bucal - Brasil Sorridente, com o objetivo de atender às necessidades de atenção básica, melhorar as condições de saúde bucal da população brasileira, e superar desigualdades sociodemográficas. As ações desse programa incluem a criação e a instalação dos Centros de Especialidades Odontológicas (CEO), prevendo a realização de procedimentos especializados à população (BRASIL, 2008). 
Os CEOs, criados em março de 2006 (Portarias No 599/GM), têm como objetivo dar continuidade ao trabalho da Estratégia Saúde da Família. Esses centros funcionam por meio de parceria entre estados, municípios e o governo federal. O Ministério da Saúde faz o repasse de uma parte dos recursos, e os estados e municípios contribuem, cada um, com outra parcela. Juntamente com os CEOs, houve a implantação de Laboratórios Regionais de Prótese Dentária LRPD (Portaria No 1572/GM de 29 de julho de 2004), que podem ser unidades próprias do município, ou unidades terceirizadas, credenciadas para confecção de próteses totais, ou próteses parciais removíveis (BRASIL, 2009).

Os países que seguem o programa de saúde bucal da OMS, como o Brasil, fazem periodicamente estudos epidemiológicos, por meio dos quais se pode aferir a média de cárie por pessoa no país. Através deles, avalia-se a eficácia dos programas governamentais de prevenção em saúde bucal, de modo a planejar outras ações. Algumas medidas preventivas básicas simples, e de comprovada eficácia, têm sido disseminadas pela OMS. Dentre elas, vale citar o autocuidado de higiene bucal; a aplicação tópica de flúor; a fluoretação de cremes dentais, da água de consumo público e de caixas d'água de escolas, creches e outros estabelecimentos; a fluoretação do leite e do sal de cozinha; o incentivo a dieta alimentar balanceada, dentre outras ações desenvolvidas para que ocorram melhorias na condição de saúde bucal da população. Os resultados da implantação de todas essas açôes só serão mensuráveis em médio e longo prazo. Serão as crianças, os jovens e os adultos da atualidade os beneficiários quando se tornarem os idosos no futuro (SILVA; VALSECKI JÚNIOR, 2000).

\section{O estatuto e os direitos do idoso quanto à atenção em saúde bucal}

Em $1^{\circ}$ de outubro de 2003, o Estatuto do Idoso (Lei no 10.741) foi aprovado pelo presidente da República, ampliando os direitos dos cidadãos com idade acima de 60 anos. Vigorando a partir de $1^{\circ}$ de janeiro de 2004, esse instrumento (que é mais abrangente que a Política Nacional do Idoso, Lei 8.842 de 4 de janeiro de 1994) institui penas severas a quem desrespeitar ou abandonar cidadãos da terceira idade (SERASA, 2008).

No Capítulo IV do Estatuto (que trata do direito à saúde), o artigo 15 determina que o idoso tenha direito à atenção integral à saúde pelo SUS. Esta 
engloba serviços que permitam sua prevenção, promoção, proteção e recuperação,

além de incluir atenção e controle das doenças prevalentes desse grupo. É direito do idoso dispor de atendimento especializado (geriátrico e gerontológico) com pessoal adequadamente treinado. Tal direito engloba também o atendimento domiciliar para aqueles impossibilitados de se locomover, residentes tanto no meio urbano quanto no rural. São ainda contemplados pelo Estatuto os idosos abrigados em instituiçôes de longa permanência que sejam conveniadas com o setor público. Vale ressaltar que essa última inclusão seria desnecessária, visto que o estatuto se aplica a todo idoso residente e presente no território brasileiro, independentemente de qualquer situação em que esteja envolvido (HEBLING; RODRIGUES, 2006).

$\mathrm{O}$ acesso aos serviços de promoção da saúde bucal é também garantido pelo Estatuto. De acordo com Alexandre Lyra (2010) "a saúde bucal comprometida pode afetar o nível nutricional, o bem-estar físico e mental e diminuir o prazer de uma vida social ativa”. Por consequência, é de responsabilidade do poder público fornecer medicamentos de uso continuado, gratuitamente, aos idosos, assim como próteses, órteses e outros recursos relativos ao tratamento, habilitação ou reabilitação oral (HEBLING; RODRIGUES, 2006, p. 53).

Os idosos são os maiores usuários de serviços médicos, embora sejam também os maiores não usuários de serviços odontológicos. Isso porque proporcionar serviços odontológicos gratuitos ou de baixo custo não aumenta necessariamente sua utilização, pois as predições mais poderosas para sua utilização por idosos são a necessidade percebida e as atitudes frente aos cuidados bucais. É por isso que o índice de edentulismo da população brasileira é muito alto. E mais, como os Centros de Especialidades Odontológicas foram implantados somente em 2006, ainda não pode ser percebida uma melhora significativa na condição de saúde bucal dos idosos. A demanda é muito alta, oriunda de anos de falta de planejamento e de tratamentos de caráter curativo e mutilador (KIYAK, 1993).

A atenção voltada à saúde do idoso tende a ser ampliada, visto que esse grupo populacional requer cuidados profissionais específicos. Grande parte da população ainda não desfruta de boas condições socioeconômicas que lhes permitam acesso ao sistema privado de saúde. Nesse caso, acabam tendo que lançar mão do sistema público, que não tem sido eficaz em cumprir com o Estatuto do Idoso (IBGE, 2000). 


\section{Material e métodos}

\section{Delineamento e universo do estudo}

Trata-se de um estudo epidemiológico do tipo transversal. Nele, a população estudada é constituída por idosos (indivíduos com 60 anos ou mais) residentes na área urbana do município de Governador Valadares, localizado na região leste do estado de Minas gerais.

\section{Amostra}

O Município possui 259.405 habitantes, sendo 21.428 idosos, representando $8,3 \%$ da população (IBGE, 2007).

Para a definição do tamanho da amostra participante da referida pesquisa, foi realizado um cálculo amostral, baseado no método de estimativa para proporção (LEVY; LEMESHOW, 1991), com nível de confiança de 95\% e precisão requerida de $5 \%$. Como padrão (p), foi utilizada a prevalência de perda dentária na população idosa, obtida por meio de levantamento epidemiológico, realizado no ano de 2004, no município, utilizando a mesma metodologia do Projeto SB2003 (BRASIL, 2003). O resultado do cálculo, após a correção para n final, feita com base no total de idosos do município, apontou uma amostra mínima de 505 idosos (já incluídos 10\% referentes a uma possível perda). Contudo, durante o período de coleta obteve-se a adesão de um total de 643 idosos, sendo 505 não institucionalizados e 138 institucionalizados. A representatividade da amostra em relação à população de idosos de Governador Valadares ficou assegurada na quantidade de participantes da pesquisa e no fato de que estes são provenientes de todos os bairros da cidade.

\section{Critérios de inclusão}

Foram incluídos idosos de ambos os sexos, com idade de 60 anos ou mais, em qualquer estado funcional, provenientes dos 22 grupos locais de terceira idade em funcionamento no município.

\section{Estudo piloto}

Para a avaliação da condição de saúde bucal dos participantes, os pesquisadores foram submetidos a um processo de calibração (interexaminador), de acordo 
com a metodologia recomendada para levantamentos básicos de saúde bucal.

Para verificação da concordância, o Índice Kappa foi empregado. Nessa etapa, os pesquisadores examinaram, em dois momentos distintos, com intervalo de sete dias, sujeitos pertencentes a uma população similar à do estudo.

Buscando testar o método de trabalho e os processos técnicos envolvidos na execução do experimento, um estudo piloto foi realizado com 10 indivíduos, utilizando todos os critérios de inclusão e exclusão. Contudo, esses indivíduos não foram considerados para o estudo principal. Segundo Marconi e Lakatos (1990), a importância do estudo piloto consiste na possibilidade de verificar se os dados a serem levantados apresentam fidedignidade, validade e operacionalidade, além de fornecer uma estimativa sobre futuros resultados.

\section{Coleta de dados}

\section{Condição de saúde bucal}

Foi realizado um levantamento epidemiológico, com o objetivo de avaliar a condição de saúde bucal. $\mathrm{O}$ exame foi realizado por pesquisadores, que estavam devidamente paramentados, utilizando máscaras e luvas descartáveis, avental, gorro e óculos de proteção. Os dados foram registrados por anotadores previamente treinados, em protocolo clínico especialmente desenvolvido para este estudo.

Para avaliar as condições dos elementos dentais, foi adotado o índice CPO-D (que totaliza o número de dentes cariados, perdidos e obturados). O CPO-D foi calculado com base no exame diagnóstico da coroa dos dentes presentes. A condição periodontal foi avaliada utilizando-se os seguintes indicadores: sangramento no momento da sondagem, profundidade de bolsa obtida a partir da sondagem e nível de inserção clínico. Esses indicadores, bem como a presença de cálculo, foram obtidos nos sítios mesial, distal, vestibular e lingual de todos os dentes presentes na cavidade bucal.

O exame da mucosa bucal e dos tecidos moles (assoalho da boca, rebordos alveolares, gengiva, língua, lábios, palatos duro e mole) foi abrangente, sistemático, e realizado na seguinte sequência: lábio e mucosa da porção anterior da boca; comissuras labiais e mucosa posterior da boca; língua; assoalho bucal; palatos duro e mole; rebordos alveolares e gengiva.

A avaliação do uso e da necessidade de prótese foi realizada registrando-se a situação da maxila e da mandíbula. 
Os resultados encontrados dentro dos parâmetros de confiabilidade para concordância entre os examinadores do índice Kappa foram classificados como "excelente concordância" (acima de 97,5 para uso e necessidade de prótese) e "ótima concordância" (acima de 95\% para CPO-D, CPI e presença de lesão). Valores acima de $90 \%$ são considerados aceitáveis, validando, dessa forma, os resultados (FRIAS, 2000).

Quando foi observada alguma necessidade de tratamento, ou ocorreu alguma dúvida de diagnóstico, o indivíduo foi encaminhado para a UNIVALE, sendo atendido no "Projeto de Diagnóstico de Lesão de Mucosa Bucal", ou na Clínica Odontológica, para realização dos procedimentos necessários.

Todos os exames foram realizados sob luz natural, com o auxílio de espelho bucal, sonda periodontal e abaixador de língua, em cadeiras comuns, cadeiras de rodas e camas, nas instituições asilares e nos grupos locais de terceira idade. Na Clínica do Curso de Odontologia, utilizou-se de cadeira odontológica.

\section{Questionário}

O questionário aplicado continha vinte e cinco questôes fechadas de múltipla escolha. As variáveis incluídas nessas questóes tinham como objetivo identificar o perfil socioeconômico, acesso a serviços odontológicos e autopercepção em saúde bucal. $\mathrm{O}$ questionário foi aplicado pelos pesquisadores antes do exame epidemiológico, em um local que apresentava comodidade, tranquilidade e silêncio.

\section{Aspectos éticos}

A pesquisa foi submetida e aprovada pelo Comitê de Ética em Pesquisa (CEP) da Universidade Vale do Rio Doce-MG, conforme parecer CEP/UNIVALE 42/2006. Todos os indivíduos que aceitaram participar do estudo leram e assinaram um Termo de Consentimento Livre e Esclarecido (TCLE). Alguns idosos institucionalizados não tiveram condiçôes de assinar o TCLE. Nesses casos, a pesquisa foi autorizada pelo responsável da instituição asilar onde o idoso era residente.

\section{Análise estatística}

Para a elaboração do presente artigo tomaram-se por referência os dados coletados junto a 428 idosos usuários da clínica de estágio supervisionado 
em odontogeriatria do curso de odontologia da FACS/UNIVALE, e junto a participantes dos 22 grupos locais de terceira idade. As variáveis analisadas foram o acesso aos serviços odontológicos, o índice CPO-D, o uso e a necessidade de próteses dentárias. Os dados foram analisados quantitativamente com o auxílio do programa Sphinx Léxica.

\section{Resultados e discussão}

A média de idade da amostra em estudo foi de 70,3 $( \pm 6,9)$ anos. Com relação ao estado civil foram identificados $43,2 \%$ de casados, $41,4 \%$ de viúvos e $15,4 \%$ de solteiros ou divorciados.

Quanto aos gêneros, 75,7\% ( $n=382)$ eram femininos e 24,4\% ( $n=123)$, masculinos. A maior presença do sexo feminino neste estudo pode estar associada ao fenômeno da "feminização da velhice", ou seja, as mulheres representam a maioria da população idosa mundial, com diferença na expectativa de vida entre os gêneros. Segundo Mastroeni et al.(2007), o padrão atual, com predomínio de mulheres acima de 60 anos em proporções que aumentam conforme progride a idade, é um aspecto de importância no planejamento dos programas locais de assistência à terceira idade.

A maior parte desses indivíduos declarou possuir de um a quatro anos de estudo (50,1\%). O fato dos participantes possuírem baixo nível de escolaridade pode ser decorrente da falta de oportunidade de acesso ao ensino, ou seja, da exclusão desses indivíduos do sistema educacional quando em idade escolar. Nessa época, grande parte da população estudava até a quarta série do primário, visto que não havia exigência de maior escolaridade para se conseguir melhores cargos e, consequentemente, melhor renda. Havia menor frequência à escola, priorizando-se o trabalho em detrimento da educação (CARVALHO; GARCIA, 2003).

Todos os participantes relataram possuir algum tipo de renda mensal, sendo esse rendimento proveniente, em grande parte, da aposentadoria (82,2\%). Ao considerar-se a renda individual, $74,5 \%$ dos idosos afirmaram viver com um rendimento mensal de um a quatro salários mínimos (o valor do salário mínimo, na época da pesquisa, era de 415,00 reais). Esse dado pode ser resultado 
da ampliação da cobertura da previdência e da legislação da assistência social estabelecida pela Constituição de 1988, que garante aos idosos carentes maiores de 65 anos um salário mínimo mensal (BRASIL, 1997).

Nos 12 meses que antecederam a entrevista, 60,6\% $(n=306)$ dos idosos afirmaram não terem ido ao dentista, 39,1\% $(\mathrm{n}=197)$ afirmaram terem tido acesso e $0,4 \%(n=2)$ nunca foram ao dentista. Segundo o Instituto Brasileiro de Geografia e Estatística, 30 milhões de brasileiros (18,7\% da população) nunca foram ao dentista, sendo que a Região Nordeste apresentou o maior índice dessas pessoas, e a Região Sul, os melhores índices relativos ao acesso a tais serviços. Foi observado também aumento de $63 \%$ na renda média dos idosos responsáveis pelos domicílios no período de 1991 a 2000. Apesar desse aumento, a condição socioeconômica dos idosos ainda não lhes permite um adequado acesso a esse tipo de serviço (IBGE, 2000).

Dos 198 idosos que tiveram a oportunidade de acesso aos serviços odontológicos, 49,0\% ( $\mathrm{n}=97)$ procuraram o Sistema Privado Liberal (Tabela 1), e o motivo da procura mais relatado foi para consulta de rotina, reparos e manutenção protética, representando $38,5 \%(\mathrm{n}=82)$ da amostra (tabela 2). Esse dado discorda com os apresentados pelo SB Brasil (BRASIL, 2003), no que se refere ao motivo do acesso na região Sudeste, onde a consulta de rotina representa $19,92 \%$ contra $48,04 \%$ de motivo relacionado à dor. No estudo realizado por Barros e Bertoldi (2002) foi observado que a maioria dos atendimentos $(69,0 \%)$ ocorreu em serviços particulares, dos quais $47 \%$ envolveram algum pagamento pelo cliente.

Tabela 1 - Distribuição do tipo de acesso aos serviços odontológicos utilizados pelos idosos pesquisados $(\mathrm{n}=198)$.

\begin{tabular}{l|l|c}
\hline \multicolumn{2}{|l|}{ Características } & Frequência n (\%) \\
\hline & Serviço privado liberal & $97(49)$ \\
& Serviço público & $81(41)$ \\
Tipo de acesso & Serviço privado (planos e convênios) & $12(6,1)$ \\
& Serviço filantrópico & $04(2,1)$ \\
& Outros & $04(2,1)$ \\
\hline
\end{tabular}



pelos idosos pesquisados ( $\mathrm{n}=198)$.

\begin{tabular}{l|l|c}
\hline \multicolumn{1}{|c|}{ Características } & Frequência n (\%) \\
\hline & Consulta de rotina (reparos e manutenção protética) & $82(38,5)$ \\
& Necessidade de prótese & $42(19,8)$ \\
Motivo da & Dor & $34(16,0)$ \\
consulta* & Cavidades nos dentes & $23(10,8)$ \\
& Outros & $19(9,0)$ \\
& Sangramento gengival & $08(3,8)$ \\
& Feridas, caroços ou manchas na boca & $05(2,4)$ \\
\hline
\end{tabular}

${ }^{*}$ múltiplas respostas

É evidente que o aumento das oportunidades de acesso odontológico a essa população faria diminuir os altos índices de cárie e doença periodontal registrados no país. O Ministério da Saúde vem trabalhando desde outubro de 2000 no que diz respeito à inclusão da saúde bucal no Programa de Saúde da Família. Essa inclusão permitiu o desenvolvimento de ações de forma integrada, beneficiando grupos populacionais prioritários (BARROS; BERTOLDI, 2002). Contudo, vale ressaltar que, enquanto esse acesso tiver caráter mutilador, os índices de edentulismo e a consequente necessidade do uso de prótese continuarão altos. A solução para esse problema requer do governo interesse e investimento principalmente na área de promoção e educação em saúde visando à prevenção.

Os dados obtidos sobre a autopercepção de saúde bucal demonstraram que $53 \%$ dos idosos a classificaram como "boa", 27,7\% como "regular", e 19,3\% como "péssima". Esses resultados mostram que os idosos têm uma percepção mais positiva que negativa sobre seus dentes. Isso quer dizer que, apesar de experimentar problemas bucais, que têm impacto negativo em suas vidas, eles, geralmente, dão um valor positivo para seus dentes.

A saúde bucal está deixando de ser medida apenas pela presença ou ausência de doenças para incorporar o ponto de vista do indivíduo. Esse fato contribuiu para que a percepção do indivíduo em relação à sua condição bucal fosse também pesquisada neste trabalho, pois trata-se de um importante indicador de saúde que sintetiza valores e expectativas culturais dos indivíduos. Os indicadores 
qualitativos não devem ser usados para diagnosticar doenças, mas usados como mais um instrumento de avaliação, que complementa as informações clínicas e possibilita identificar pessoas ou populações que necessitam de ações curativas, preventivas ou educativas (MINAYO, 2003).

Em relação ao CPO-D foram encontrados 394 dentes cariados, 11.863 perdidos e 1.714 obturados (tabela 3), tendo o valor do CPO-D de 27,6. Esse valor é semelhante ao encontrado pelo SB Brasil (2003), que para a região sudeste, na faixa etária de 65 a 74 anos, encontrou um CPO-D de 28,61. Em outros estudos presentes na literatura, como os de Carneiro et al. (2005), Silva e Valsecki Júnior (2000), também foi encontrado um alto índice no valor do componente "P", e isto se dá devido à falta de uma prática preventiva por parte dos cirurgiōes-dentistas, que há alguns anos vêm realizando extrações desnecessárias e eventualmente iatrogênicas, o que fez aumentar o índice de edêntulos no país. A perda parcial ou total dos elementos dentais retrata um processo irreversível e cumulativo. É um dos principais problemas encontrados nessa população, devido ao grande número de idosos atingidos e às consequências que esse fato pode ter em suas vidas, em relação à saúde.

Tabela 3 - Distribuição dos valores dos componentes do índice CPO-D dos idosos pesquisados $(\mathrm{n}=505)$

\begin{tabular}{c|l|c|c}
\hline \multicolumn{2}{c|}{ Características } & Frequência n (\%) & Média \\
\hline \multirow{4}{*}{ Componentes do CPO-D } & Cariado & $394(2,5)$ & 0,78 \\
& Perdido & $11863(85,3)$ & 23,49 \\
& Obturado & $1714(12,2)$ & 3,40 \\
& CPO-D & ----- & 27,6 \\
\hline
\end{tabular}

O Projeto SB Brasil - Levantamento Epidemiológico das Condições de Saúde Bucal da População Brasileira - realizado entre os anos 2002 e 2003 teve por objetivo produzir informações sobre as condições de saúde bucal da população brasileira e subsidiar o planejamento-avaliação de ações nessa área nos diferentes níveis de gestão do Sistema Único de Saúde.

Os dados desse levantamento revelaram uma situação de saúde bucal considerada insatisfatória para a população idosa. O índice CPOD (a soma 
de dentes cariados, perdidos e obturados por cárie num indivíduo) apresentou expressivo incremento com o avançar da idade, e na faixa etária dos 65 aos 74 anos alcançou 27,79, sendo explicado em grande parte pelo componente "perdido" (92\% do índice). Somente $10 \%$ dos idosos conservavam ainda 20 ou mais dentes. Idosos de cidades com menos de 50.000 habitantes apresentaram médias mais baixas de dentes hígidos e médias maiores de dentes perdidos (BRASIL, 2004).

A meta preconizada pela Organização Mundial da Saúde para o ano 2000, na faixa etária de 65-74 anos, era de que 50\% da população deveriam ter vinte dentes ou mais na cavidade bucal. Os dados obtidos no presente trabalho e em outros estudos como os de Meneguim e Saliba (2000) apud Colussi e Freitas (2002); Pucca Jr. (2002); Silva e Valsecki Júnior (2000); SB-Brasil (2003)²2 se apresentam aquém da meta estabelecida.

Em relação ao uso de prótese, prevaleceu aqueles que não utilizavam nenhum tipo com 44,2\% ( $\mathrm{n}=557)$. Dos que utilizavam prótese, houve prevalência da total removível com 38,7\% ( $\mathrm{n}=488)$ seguido da prótese parcial removível com 15,3\% $(\mathrm{n}=192)$ e da prótese fixa com $2,1 \%(\mathrm{n}=26)$ (tabela 4). A maioria dos idosos não apresentou necessidade de uso de prótese representando $47,7 \%(n=608)$ da amostra. Dentre os que dela necessitavam, a maior demanda correspondeu à prótese total com 32,8\% $(\mathrm{n}=418)$, seguido da prótese parcial com 19,4\% $(\mathrm{n}=247)$ e da prótese fixa com $0,4 \%(n=4)$ (tabela 5). Como a instalação dos centros de especialidades odontológicas e dos Laboratórios Regionais de Próteses Dentárias é ainda recente, não se pode atribuir esse fato à baixa necessidade do uso de prótese encontrado nesse estudo. Espera-se que, em longo prazo, tais índices se reduzam ainda mais, visando cumprir as metas traçadas pela OMS para 2010. Essa meta almeja que apenas $5 \%$ da população, na faixa etária entre 65 a 74 anos, apresente edentulismo.

Tabela 4 - Distribuição do uso de prótese em idosos $(\mathbf{n}=505)$ de acordo com o tipo

\begin{tabular}{l|l|c}
\hline \multicolumn{2}{c|}{ Características } & Frequência n (\%) \\
\hline \multirow{3}{*}{ Necessidade de prótese } & Sem necessidade & $608(47,7)$ \\
& Prótese total removível & $418(32,8)$ \\
& Prótese parcial removível & $247(19,4)$ \\
& Prótese fixa & $04(0,4)$ \\
\hline
\end{tabular}


Tabela 5 - Distribuição da necessidade de prótese em idosos $(n=505)$ de acordo com o tipo.

\begin{tabular}{l|l|c}
\hline \multicolumn{2}{c|}{ Características } & Frequência n (\%) \\
\hline \multirow{4}{*}{ Uso de prótese } & Sem prótese & $557(44,2)$ \\
& Prótese total removível & $488(38,7)$ \\
& Prótese parcial removível & $192(15,3)$ \\
& Prótese fixa & $26(2,1)$ \\
\hline
\end{tabular}

\section{Conclusões}

Os dados epidemiológicos dos idosos residentes no município pesquisado demonstram que a condição de saúde bucal pode ser classificada como precária, pois apresenta elevada perda dentária, demandando tratamento odontológico especializado. Foi possível observar que o Edentulismo permanece como importante problema de saúde bucal entre os idosos examinados. Nesse contexto é necessário que se estruturem serviços de saúde bucal em vários níveis de atenção, construindo uma rede hierarquizada e descentralizada durante o ciclo de vida do indivíduo.

Os dados obtidos a partir da análise da autoavaliação da condição bucal contrastaram com o exame clínico realizado, pois vários indivíduos tiveram uma visão positiva da sua condição bucal, o que está em desacordo com os dados clínicos que revelaram, realmente, condições bucais insatisfatórias.

Espera-se que a atual Política Nacional de Saúde Bucal - Programa Brasil Sorridente - implantada no município, venha ampliar e qualificar a oferta de serviços odontológicos especializados, por meio de Centros de Especialidades Odontológicas (CEO), e, consequentemente, resolver uma demanda de atenção em saúde bucal mais resolutiva para esse grupo da população. Desenvolver ações dirigidas a esse grupo não significa deixar de dar atenção prioritária a outros, mas distribuir de maneira equilibrada os recursos, de acordo com a atual situação demográfica e epidemiológica.

Embora muitas ações no âmbito da saúde bucal tenham sido implantadas, os resultados das pesquisas indicam que as metas da OMS para o ano de 2010 não foram cumpridas. No tocante especificamente ao idoso, tais metas chegam a ser surrealistas. Enfim, não é possível pensar numa condição de saúde bucal satisfatória para esse grupo populacional, se este não foi beneficiado por programas de educação e prevenção durante a fase da infância e adolescência. 
Nota de Fim: Artigo desenvolvido a partir de dados coletados na pesquisa

Levantamento epidemiológico da saúde bucal de idosos institucionalizados e não-institucionalizados de Governador Valadares-MG, 2007-2008. Esta foi aprovada e fomentada pelo Programa de Pesquisa para o "SUS", após submissão ao Edital de Demanda Induzida 005/2006 da FAPEMIG.

\section{Referências}

ANTUNES, J.L.F.; PERES, M.A. Epidemiologia da saúde Bucal. Rio de Janeiro: Guanabara Koogan, 2006. cap.1, p. 4.

BARROS, A.J.D.; BERTOLDI, A.D. Desigualdades na utilização e no acesso a serviços odontológicos: uma avaliação em nível nacional. Ciência \& Saúde Coletiva. Pelotas, v.7, n. 4, p. 709-717, 2002.

BELTRĀO, K.I.; CAMARANO, A.A.; KANSO, S. Dinâmica populacional brasileira na virada do século XX. Rio de Janeiro: IPEA, 2004.

BRASIL. Constituição da República Federativa do Brasil, 1988. São Paulo: Revista dos Tribunais; 1997.

BRASIL. Ministério da Saúde. 2000. Disponível em: <http://dtr2004.saude.gov.br/dab/ cnsb/especialidades.php>. Acesso em: 27 maio 2009.

Disponível em: <http://portal.saude.gov.br/portal/saude/visualizar_texto. cfm?idtxt=21125 Acesso em: 25 out 2008.

Disponível em: <http://portal.saude.gov.br/portal/saude/profissional/visualizar_ texto.cfm?idtxt=25086\&janela=1>Acesso em: 10 jun 2009.

Projeto SB Brasil: condições de saúde bucal da população brasileira, resultados principais. Brasília: MS, 2003.

. Projeto SB Brasil - 2003: condição de saúde bucal da população brasileira 20022003. Resultados parciais. Brasília: Ministério da Saúde, 2004.

CAMARANO, A.A. Envelhecimento da população brasileira: uma contribuição demográfica.. Rio de Janeiro, IPEA, 26 p., jan. 2002 (Texto Para Discussão n. 858).

. Mecanismo de proteção social para a população idosa brasileira. Rio de Janeiro, IPEA, 20 p., abril 2006 (Texto Para Discussão n. 1179). Disponível em: <http://www.ipea. gov.br/pub/td/2006/td_1179.pdf>. Acesso em: 26 nov. 2008.

CAMPOS, N.O.B. O Ritmo de declinio nas taxas de mortalidade dos idosos nos estados do Sudeste 1980-2000. 2004. 59 f. Dissertação (Mestrado) - Faculdade de Ciências Econômicas, Universidade Federal de Minas Gerais, Belo Horizonte, 2004.

CARNEIRO, R.M.V. et al. Saúde bucal de idosos institucionalizados, zona leste de São Paulo, Brasil, 1999. Cad. Saúde Pública, Rio de Janeiro, v. 21, n. 6, p. 1709-1716, nov./dez. 2005. 
CARVALHO, J.A.M.; GARCIA, R.A. O envelhecimento da população brasileira: um enfoque demográfico. Cad Saúde Pública, v.19, n.3, p. 725-733, 2003.

COLUSSI, C.F.; FREITAS, S.F.T. Aspectos epidemiológicos da saúde bucal do idoso no Brasil. Cad. Saúde Pública, Rio de Janeiro, v.18, n.5, p.1313-1320, set/out 2002.

DIAS, L.C.S. et al. Interferência da condição de saúde bucal do idoso em sua vida social e afetiva. 2008. Disponível em: <http://www.cedeplar.ufmg.br/seminarios/seminario_ diamantina/2008/D08A135.pdf>. Acesso em: 23 nov. 2008.

ETTINGER, R.L. Clinical training for geriatric dentistry. Gerodont, v. 3, n. 4, p. 275-279, April 1987.

FILHO, J.M.C.; RAMOS, L.R. Epidemiologia do envelhecimento no Nordeste do Brasil: resultados de inquérito domiciliar. Rev. Saúde Pública, v. 33, n.5, p. 445-453, 1999.

FRIAS, A.C. Estudo da confiabilidade do levantamento das condições de saúde bucal. 2000. Dissertação (Mestrado em Saúde Pública) Faculdade de Saúde Pública, Universidade de São Paulo, São Paulo.

GIACOMIN, K.C. et al. Projeto Bambuí: um estudo de base populacional da prevalência e dos fatores associados à necessidade de cuidador entre idosos. Cadernos de Saúde Pública, v. 21, n. 1, p. 80-91, set. 2005.

HAMILTON, I.S. Uma introdução a Psicologia do Envelhecimento 3. ed. Porto Alegre: Artmed, 2002.

HEBLING, E.; RODRIGUES, C.K. Estatuto do idoso e a saúde bucal. Robrac, Piracicaba, v.15 n.39, p. 56-63, 2006.

INSTITUTO BRASILEIRO DE GEOGRAFIA E ESTATÍSTICA. Censo Demográfico, 2000. Disponível em: <http://www.ibge.gov.br>. Acesso em 21 nov. 2008.

. Pesquisa Nacional por Amostra de Domicílios, 1998. Disponível em: < http://www.

ibge.gov.br/home/estatistica/populacao/trabalhoerendimento/pnad98/saude/analise.shtm > Acesso em: 21 nov.2008.

KIYAK, H.A. Oral health promotion in old age. In: Oral health promotion. New York: Oxford University Press, p. 207-232, 1993.

LEVY, P.S.; LEMESHOW, S. Sampling of populations: methods and applications. New York, 1991.

LYRA, A. Cuidados com a saúde bucal na terceira idade garantem vida social ativa, 2010.

Disponível em:http://www.campograndenoticias.com.br/saude/cuidados_saude_bucal_ idosos_garantem_vida_social_ativa.htm Acesso em: 16 de agosto de 2011.

MARCONI, M.A.; LAKATOS, E.M. Técnicas de pesquisa. 2 ed. São Paulo: Atlas, 231 p., 1990. 
MASTROENI, M.F. et al. Perfil demográfico de idosos da cidade de Joinville, Santa Catarina: estudo de base domiciliar. Rev Bras Epidemiol, v.10, n.2, p.190-201, 2007.

MINAYO, M.C.S. et al. Qualidade de vida e saúde: um debate necessário. Ciência e Saúde Coletiva, v.1, n.5, p.5-18, 2000.

MONTENEGRO, F.B. Odontogeriatria: uma nova opção de trabalho no Século XXI. 2003. Disponível em: http://www.wwow.com.br/portal/colunas/colunas. asp? secao $=1 \&$ sc $=13 \&$ scol=1\&id=34 Acesso em: 05 dez. 2008.

MORAES, E.N. Princípios Básicos de Geriatria e Gerontologia. Belo Horizonte: Coopmed, 2008.

PUCCA JÚNIOR, G.A. A saúde bucal do idoso: aspectos demográficos e epidemiológicos. Abril/2002. Disponível em: <http://www.odontologia.com.br/artigos. asp?id=81\&idesp=19\&ler=5>. Acesso em: 21 nov. 2008.

RAMOS, L.R.; VERAS, R.P.; KALACHE, A. Envelhecimento populacional: uma realidade brasileira. Revista de Saúde Pública, v.21, p.211-224, 1987.

SERASA. O Estatuto do idoso. Guia Serasa de orientação ao cidadão. Disponível em: <http:// www.serasa.com.br/guiaidoso/20.htm>. Acesso em: 30 jun. 2008.

SILVA S.R.C.; VALSECKI JÚNIOR, A. Avaliação das condições de saúde bucal dos idosos em um município brasileiro. Rev. Panam Salud Publica, Washington, v. 8, n. 4, p. 268-271, maio 2000.

TOMMASI, A.F. Estomatologia geriátrica. In: . Diagnóstico em Patologia Bucal. São Paulo: Medisa, 1987. p. 493-499.

VERAS, R.P.; CALDAS, C.P. Promovendo a saúde e a cidadania do idoso: o movimento das universidades da terceira idade. Ciências Saúde Coletiva, Rio de Janeiro, v.9, n.2. abr 2004.

VIEIRA, W.S. Profissional atuante comenta o quadro atual e aponta rumos do mercado. 2003. Disponível em: < http://www.drashirleydecampos.com.br/noticias/10635 > Acesso em: 07 maio 2009.

WORLD HEALTH ORGANIZATION. Recent advances in oral health. Geneva: WHO, 1992. (WHO Technical Report Series, 826). 


\section{Abstract}

\section{Comparative study of the oral health status of non-institutionalized elderly from Governador Valadares- $M G$, with the goal proposed by the World Health Organization, 2010}

This study aimed to compare the oral health status of non-institutionalized elderly from Governador ValadaresMG, with the goal proposed by the World Health Organization for the year 2010. We used the database developed by the research group "Health, Individual and Society", from Vale do Rio Doce University. We assessed access to dental services, the DMFT index and the use and the use and need for prostheses in 505 elderly. With regard to access to dental services, $61.8 \%$ of seniors said they had not gone to the dentist in the past 12 months preceding the interview. Of these, 37.9\% reported having sought the public system due to routine consultation, denture repairs and maintenance. The result of the DMFT index was 27.9. As for the use and need of prostheses, it was found that $46.9 \%$ of seniors used the removable total, $33.3 \%$ did not use any type, $54.1 \%$ had no need to use and $23.8 \%$ needed removable dentures. From the data obtained, we conclude that the oral health status of elderly subjects is poor, being far from the standard set by the WHO goals for the year 2010. This fact points to the need for investments in oral health, so that long-term goals are met.

> Key words: elderly, oral health, World Health Organization. 